\title{
The Primary Tumor Characteristics of Non-Small Cell Lung Cancer on Pet/Ct
} \author{
$\operatorname{Tri}^{6}$ \\ ${ }^{1}$ Quangngai hospital, Vietnam \\ ${ }^{2}$ Choray hospital, Vietnam \\ ${ }^{3}$ Pham Ngoc Thach university of medicine, Vietnam \\ ${ }^{4}$ Danang hospital, Vietnam \\ ${ }^{5}$ Choray hospital, Vietnam \\ ${ }^{6}$ Danang hospital, Vietnam \\ *Corresponding author: Tran Phu Tri, Danang hospital, Vietnam
}

Tran Hoang Vi ${ }^{1}$, Le Minh Quang ${ }^{2}$, Dang Vinh Hiep ${ }^{3}$, Tran Phu Tri ${ }^{4 *}$, Le Cong Tri ${ }^{5}$ and Vo Thi Minh

ARTICLE INFO

Received: 蔧 July 01, 2020

Published: July 15, 2020

Citation: Tran Hoang Vi, Le Minh Quang, Dang Vinh Hiep, Tran Phu Tri, Le Cong Tri,Vo Thi Minh Tri. The Primary Tumor Characteristics of Non-Small Cell Lung Cancer on Pet/Ct. Biomed J Sci \& Tech Res 28(5)2020. BJSTR. MS.ID.004720.

\section{ABSTRACT}

Objective: To explore the location, tumor diameter and SUVmax on PET/CT of primary tumor in non-small cell lung cancer.

Subjects and Methods: Patients diagnosed with non-small cell lung cancer based on pathology results were retrospective analyzed at Oncology and Nuclear Medicine Department - Bach Mai Hospital, from November 2015 to October 2018. They were underwent 18F-FDG PET-CT scans before the treatment. The variables include location, tumor diameter, SUVmax of the primary tumor.

Results: 318 NSLC patients (220 men and 98 women), including 278 cases of adenocarcinoma, 12 cases of large cell carcinoma; 28 cases of squamous cell carcinoma. The smallest tumor is $0.9 \mathrm{~cm}$ in diameter, the largest is $15.9 \mathrm{~cm}$; the mean tumor diameter is $4.77 \pm 2.41 \mathrm{~cm}$. Tumors were present in all lobes, with the upper lobes accounting for the highest proportion (36.8\%), followed by the lower lobe (29.2\%), main bronchus (12.9\%). The smallest SUVmax is 1.4; largest is 36.4; the mean of SUVmax is $10.95 \pm 5.42$. The primary tumor SUVmax at different lobar sites were not significant $(\mathrm{p}>0.05)$.

Conclusion: PET/CT is a very good imaging technique for detecting the primary lung tumor of non-small cell lung cancer.

\section{Introduction}

Lung cancer is a fairly common malignancy of the respiratory system, the most common cause of cancer death in Europe in 2006 (about 334,800 deaths), after prostate cancer and is the most common type of cancer in men. The morbidity and mortality rates in 2006 were 75.3 and 64.8 / 100,000 people / year [1]. According to the statistics of the American Cancer Society in 2006, lung cancer was the leading cause of death in cancers (about 162,460 in 2006), accounting for about $13 \%$ of all cancers and $28 \%$ of the Cancer deaths [2]. In Vietnam, according to cancer epidemiological records in 2004, lung cancer is the most common cancer in the country, ranking first among men with the incidence rate in Hanoi of 39.8 / 100,000 [3].Lung cancer if detected late, the prognosis is very bad, the mortality rate is very high and death within a short time after the disease is detected. Early diagnosis and evaluation of the stage of lung cancer is a necessary and urgent need. Including important help of the diagnostic means. Conventional X-rays and computer 
tomography are two techniques for casualty survey. However, assessing the stage of the tumor is still limited.

In recent years, the role of PET / CT in diagnosing and assessing the stage of non-small cell lung cancer has been increasingly confirmed. However, in our country, there is no research to mention the role of PET / CT in assessing stage of non-small cell lung cancer.

\section{Materials and Methods}

The subjects selected were patients with Non-small cell lung cancer diagnosed by pathological anatomy and were taken PET / CT according to the method selected in the study.

Place: performed at the Department of Oncology and Nuclear Medicine - Bach Mai Hospital. Study period: 11 / 2015-10 / 2018.

Convenient sampling: we have selected 318 cases eligible for inclusion in the study

Steps to take:

a) Step 1: Make a list of cases diagnosed with non-small cell lung cancer diagnosed at Bach Mai Hospital. All patients admitted to the hospital have been diagnosed with non-small cell lung cancer and have PET-CT scan.

b) Step 2: Find and process images and save the results backed up to a large capacity hard drive on Efilm software platform.

c) Step 3: Reading films, recording, evaluating image features, measuring $\mathrm{u}$ (according to sample medical records). Read the results for a research project conducted by the author and two imaging experts with extensive clinical practice experience.

d) Step 4: Statistics and data processing

\section{Results}

318 patients with non-small cell lung cancer (220 male, 98 female), of which: 278 cases of adenocarcinoma lung cancer, 12 cases of large cell lung cancer; 28 cases of squamous cell lung cancer(Tables 1-3).

Table 1: Primary tumor size.

\begin{tabular}{|c|c|c|}
\hline Primary tumor size & $\begin{array}{c}\text { Number of } \\
\text { tumors }\end{array}$ & Rate \% \\
\hline$\leq 1 \mathrm{~cm}$ & 2 & 0,6 \\
\hline$>1-2 \mathrm{~cm}$ & 19 & 6,0 \\
\hline$>2-3 \mathrm{~cm}$ & 67 & 21,1 \\
\hline$>3-4 \mathrm{~cm}$ & 65 & 20,4 \\
\hline$>4-5 \mathrm{~cm}$ & 49 & 15,4 \\
\hline$>5-7 \mathrm{~cm}$ & 59 & 18,6 \\
\hline$>7 \mathrm{~cm}$ & 57 & 17,9 \\
\hline Total & 318 & 100,0 \\
\hline $\begin{array}{c}\text { The smallest, the biggest } \\
\text { medium }\end{array}$ & The smallest: $0.9 \mathrm{~cm}$; The largest: $15.9 \mathrm{~cm}$ \\
\hline
\end{tabular}

Note: Primary tumors were found at all sizes with equal ratio, the smallest tumor was $0.9 \mathrm{~cm}$, the largest was $15.9 \mathrm{~cm}$; Average $4.77 \pm 2.41 \mathrm{~cm}$.

Table 2: The location of the primary tumor.

\begin{tabular}{|c|c|c|c|c|c|c|}
\hline \multirow{2}{*}{ Tumor location } & \multicolumn{2}{|c|}{ Left Lung } & \multicolumn{2}{|c|}{ Right lung } & \multirow{2}{*}{$\begin{array}{c}\text { General } \\
\mathrm{n}\end{array}$} & \multirow[b]{2}{*}{$\%$} \\
\hline & $\mathrm{n}$ & $\%$ & $\mathrm{n}$ & $\%$ & & \\
\hline The bottom of the lungs & 2 & 1,4 & 0 & 0,0 & 2 & 0,6 \\
\hline Peak of lungs & 9 & 6,2 & 14 & 8,1 & 23 & 7,2 \\
\hline Original bronchus & 22 & 15,1 & 19 & 11,0 & 41 & 12,9 \\
\hline Lung umbilicus & 8 & 5,5 & 13 & 7,6 & 21 & 6,6 \\
\hline Lower lobe & 45 & 30,8 & 48 & 27,9 & 93 & 29,2 \\
\hline Middle lobe & 0 & 0,0 & 21 & 12,2 & 21 & 6,6 \\
\hline Upper lobe & 60 & 41,1 & 57 & 33,1 & 117 & 36,8 \\
\hline Total & 146 & 100 & 172 & 100 & 318 & 100 \\
\hline
\end{tabular}

Note: The tumor is present in all the pulmonary lobes, in which the upper lobe accounts for the highest proportion (36.8\%), the lower lobe $(29.2 \%)$, the original bronchus $(12.9 \%)$.

Table 3: SUVmax by location of primary tumor.

\begin{tabular}{|c|c|c|}
\hline Tumor location & Number of tumor & SUVmax (TB \pm SD) \\
\hline The bottom of the lungs & 2 & $10,30 \pm 1,84$ \\
\hline Đỉnh phổi & 23 & $13,12 \pm 7,57$ \\
\hline Peak of lungs & 41 & $11,80 \pm 6,27$ \\
\hline Lung umbilicus & 21 & $10,48 \pm 4,50$ \\
\hline Lower lobe & 93 & $10,72 \pm 5,59$ \\
\hline Middle lobe & 21 & $8,48 \pm 3,32$ \\
\hline Upper lobe & 117 & $10,94 \pm 4,82$ \\
\hline
\end{tabular}


Note: The value of SUVmax primary tumor at different lung positions was not significant ( $p>0.05)$.

\section{Discussion}

Primary tumors were found in all sizes with similar proportions, the smallest tumor was $0.9 \mathrm{~cm}$, the largest was $15.9 \mathrm{~cm}$; Average 4.77 $\pm 2.41 \mathrm{~cm}$. The tumor is present in all hydrocephalus, in which the upper lobe accounts for the highest proportion (36.8\%), followed by the lower lobe (29.2\%), and the base bronchus (12.9\%). SUVmax minimum primary tumor 1.4; the largest is 36.4; Average $10.95 \pm$ 5.42. SUVmax value of primary tumor at different lung positions had no significant difference ( $p>0.05$ ). Some studies have used a single fixed threshold for SUVs of 2.5, while others have applied SUV 3.0 thresholds to distinguish benign and malignant lesions [4]. SUVs can be influenced by many factors, including tumor characteristics and plasma glucose levels [5]. Not all lesions in the lung with increased metabolism have to be determined by histopathology. Therefore PET / CT survey plays a very important role in the diagnosis.

Park SB et al. Measured SUV max, average SUV, MTV conversion volume and calculated TLG values. The results show that SUVmax, Medium SUV, MTV, and TLG are: $11.8 \pm 4.3,5.1 \pm 1.0,150.4 \pm 169.9$ $\mathrm{cm} 3$ and $788.3 \pm 826.5$. The study shows that, with cutoff values of max SUV (12.0), average SUV (5.0), MTV (100 cm3) and TLG (555). From this cutoff, patients were divided into two groups: the highvalue group above the cut-off threshold of MTV and the TLG had a lower survival time than the low-value group. Thus, MTV and TLG highly predict patients with short survival. The difference between the values of SUV max, average SUV high and low and the survival time difference was not statistically significant. Also, according to the author's study, there is a very strong correlation between MTV and TLG ( $\mathrm{r}=0.963, \mathrm{P}<0.001)$ [4].

SUV is a semi-quantitative indicator that assesses the tumor's FDG uptake. On that basis, collect metabolic assessment information [4]. However, some studies show that SUVs are not an independent prognostic factor when compared to the period [6] In Park SB et al. [4], SUVmax was not an independent prognostic factor with survival time on univariate analysis $(P=0.168)$. This author's result is also consistent with previous reports that have found that SUVmax is not an independent prognostic factor for survival time [6]. This can be partly explained by the influence of the partial volume and the dependence of SUVmax on tumor size. SUV is a unique voxel measurement, with the points with the highest radioactive concentration in the Volume of Interest (VOI) So. may not reflect the heterogeneous nature of the tumor and it is easily affected by noise interferences in statistics and voxel size [5]

Difference of SUVmax is only representative for single voxel. In the meanwhile, MTV and TLG represent the extent of FDG uptake of the whole tumor and have been considered as a better predictor of index than SUVmax, giving good applicability in clinical practice in the survey. types of malignancies [7]. The clinical signs and symptoms of lung cancer are often vague or nonspecific, including cough, chest pain, hoarseness, recurrent pneumonia and coughing up blood. Conventional X-rays help find lung nodules or tumors, but often produce false-negative results, especially in early-stage disease [8]. In a study of 396 lung radiographs of proven lung cancer patients from 1992-1995, nearly $20 \%$ of lung cancer was undetectable, usually with nodules less than $1.6 \mathrm{~cm}$ in diameter [9]. Many cases were not detected on radiographs, until lesions were detected relatively large in size [8]. Computerized tomography has greatly improved compared to pulmonary X-ray in detecting small lesions [10].

For non-small cell lung cancer, PET / CT is better than computerized tomography for distinguishing benign and malignant lesions and is far more valuable in the evaluation of invasive lymphadenopathy and distant metastases. Other officials [11]. Research by Antoch et al. [12] shows that the superior detection of PET / CT scans compared with PET scans or computed tomography in evaluating T-stage small cell non-small cell lung cancer (accuracy $94 \%$ with PET / CT versus $75 \%$ of PET or computerized tomography, stage N (93\% accuracy with PET / CT and 63\% for computerized tomography and $89 \%$ for PET alone). PET / CT is also better at detecting distant metastases than CT or PET alone. Although the accuracy of PET / CT is higher than that of computerized tomography in lung cancer assessment. However, in some cases of non-malignant lesions such as inflammation, granulomatosis (mycobacterial infection, sarcoidosis), recent surgery may have a false positive result with FDG uptake[13].

\section{Conclusion}

The smallest tumor is $0.9 \mathrm{~cm}$, the largest is $15.9 \mathrm{~cm}$ Average $4.77 \pm 2.41 \mathrm{~cm}$. The tumor was present in all hydro-lung, in which the upper lobe accounted for the highest proportion (36.8\%), followed by the lower lobe (29.2\%), and the original bronchus (12.9\%). SUVmax minimum 1.4; the largest is 36.4; Average 10.95 \pm 5.42 . PET / CT is a very good imaging technique for detecting primary tumors of non-small cell lung cancer.

\section{References}

1. Soret M, S L Bacharach, I Buvat (2007) Partial-volume effect in PET tumor imaging. J Nucl Med 48(6): 932-945.

2. (2006) Cancer Facts and Figures.

3. Nguyen Ba Đuc (2006) The situation of cancer in Vietnam 2001-2004 period. Journal of Practical Medicine 9-17.

4. Kim B S, In Joo Kim , Seong Jang Kim , Hyun Yeol Nam, Kyoung June Pak, et al. (2011) The Prognostic Value of the Metabolic Tumor Volume in FIGO stage IA to IIB Cervical Cancer for Tumor Recurrence: Measured by F-18 FDG PET/CT. Nucl Med Mol Imaging 45(1): 36-42.

5. Oh J R, Ji Hyoung Seo, Ari Chong, Jung-Joon Min, Ho Chun Song, et al (2012) Whole-body metabolic tumour volume of 18F-FDG PET/CT improves the prediction of prognosis in small cell lung cancer. Eur J Nucl Med Mol Imaging 39(6): 925-935. 
6. Park S B, Joon Young Choi, Seung Hwan Moon, Jang Yoo, Hojoong Kim, et al. (2014) Prognostic value of volumetric metabolic parameters measured by [18F] fluorodeoxyglucose-positron emission tomography/ computed tomography in patients with small cell lung cancer. Cancer Imaging 14: 2.

7. Lobrano M B (2006) Partnerships in oncology and radiology: the role of radiology in the detection, staging, and follow-up of lung cancer. Oncologist 11(7): 774-779.

8. Quekel L G, A G Kessels, R Goei, J M van Engelshoven (1999) Miss rate of lung cancer on the chest radiograph in clinical practice. Chest 115(3): 720-724.

9. Sone S, F Li, Z G Yang, S Takashima, Y Maruyama, et al. (2000) Characteristics of small lung cancers invisible on conventional chest radiography and detected by population based screening using spiral CT. Br J Radiol 73(866): 137-145.

ISSN: 2574-1241

DOI: $10.26717 /$ BJSTR.2020.28.004720

Tran Phu Tri. Biomed J Sci \& Tech Res

(c) (P) This work is licensed under Creative Submission Link: https://biomedres.us/submit-manuscript.php
10. Schrevens L, Natalie Lorent, Christophe Dooms, Johan Vansteenkiste (2004) The role of PET scan in diagnosis, staging, and management of non-small cell lung cancer. Oncologist 9(6): 633-643.

11. Antoch G, Jörg Stattaus, Andre T Nemat, Simone Marnitz, Thomas Beyer, et al. (2003) Non-small cell lung cancer: dual-modality PET/CT in preoperative staging. Radiology 229(2): 526-533.

12. Kavanagh P V, Aaron W Stevenson, Michael Y Chen, Paige B Clark, et al. (2004) Nonneoplastic diseases in the chest showing increased activity on FDG PET. AJR Am J Roentgenol 183(4): 1133-1141.

13. Sorensen M, M Pijls Johannesma, E Felip, ESMO Guidelines Working Group (2010) Small cell lung cancer: ESMO Clinical Practice Guidelines for diagnosis, treatment and follow-up. Ann Oncol 21 Suppl 5: v120-

$\begin{array}{ll}\text { BIOMEDICAL } & \text { Assets of Publishing with us } \\ \text { RESEARCHES } & \text { - Global archiving of articles } \\ \text { - Immediate, unrestricted online access } & \text { - Rigorous Peer Review Process } \\ & \text { - Authors Retain Copyrights } \\ \end{array}$

